\section{Importancia de la predicción de bacteriemia en los servicios de urgencias}

\section{Importance of prediction of bacteremia in the emergency departments}

\section{Sr. Editor:}

He leído con interés el reciente artículo publicado en su revista por Cuervo y cols. ${ }^{1}$, en relación al desarrollo $\mathrm{y}$ validación de un modelo predictor para bacteriemia en pacientes hospitalizados por el servicio de urgencia (SU) con sospecha de infección. Quisiera felicitar a los autores por su trabajo y por recordarnos a todos que uno de los campos de mejora, claramente conocidos y no resueltos aún en los SU, se refiere a la adecuada indicación y obtención de los hemocultivos ${ }^{2}$.

La sospecha y la posterior detección de bacteriemia desde los SU tienen un importante significado diagnóstico, terapéutico y pronóstico ${ }^{3,4}$, por lo que cualquier modelo predictivo válido y cualquier herramienta de ayuda a los mismos deben ser explorados e incorporados a nuestra práctica clínica, una vez conseguida la evidencia de su utilidad. $\mathrm{Y}$ en ello estamos dedicados muchos grupos de infectólogos y urgenciólogos ${ }^{5,6}$; debido a la trascendencia que tiene esta situación para el paciente como para el sistema (toma de hemocultivos ${ }^{2}$, administración adecuada y precoz del antimicrobiano ${ }^{7}$, decisión de alta o ingreso ${ }^{6}$, etc.). Buena prueba de todo ello son las numerosas publicaciones e iniciativas al respecto de los últimos años. Por ello, la propuesta de los autores para encontrar un modelo de predicción útil, sencillo y aplicable en los SU con sólo signos y datos clínicos (temperatura $\geq 38^{\circ} \mathrm{C}$ y escala de Glasgow $<15$ ) y analíticos (recuento plaquetas $\leq 150.000$ céls $\left./ \mathrm{mm}^{3}\right)^{1}$, como ya han hecho otros expertos ${ }^{2,3}$, parece muy pertinente y valiosa.

En nuestra experiencia durante años, tras el análisis

Tabla 1. Recomendaciones de toma de hemocultivos en el servicio de urgencias en función de la probabilidad de bacteriemia

\begin{tabular}{|c|c|c|c|}
\hline \multirow[t]{3}{*}{ Situación clínica } & \multicolumn{3}{|c|}{ Concentraciones de procalcitonina $(\mathrm{ng} / \mathrm{ml})$} \\
\hline & $<0,5$ & $0,5-1$ & $>1$ \\
\hline & $\begin{array}{l}\text { Bajo riesgo } \\
\text { bacteriemia }\end{array}$ & $\begin{array}{c}\text { Moderado riesgo } \\
\text { bacteriemia }\end{array}$ & $\begin{array}{l}\text { Alto riesgo } \\
\text { bacteriemia }\end{array}$ \\
\hline Sin criterios de sepsis & No HC & $\begin{array}{c}\text { Valorar } \\
\text { individualmente }\end{array}$ & Sí \\
\hline Sepsis & $\begin{array}{c}\text { Valorar } \\
\text { individualmente }\end{array}$ & Sí & Sí \\
\hline Sepsis grave-shock séptico & Sí & Sí & Sí \\
\hline
\end{tabular}

Sepsis: Síndrome de respuesta inflamatoria sistémica más infección; HC: hemocultivos. Adaptada de referencia 6. del rendimiento de los hemocultivos indicados en nuestro SU y la búsqueda de herramientas objetivas que nos puedan ayudar a mejorar la sospecha de bacteriemia ${ }^{8,9}$, hemos incluido además de las variables indicadas por Cuervo et $\mathrm{al}^{1}$, otros datos analíticos (como el lactato y la procalcitonina) y la situación clínica del paciente con sospecha de bacteriemia (de acuerdo con los criterios clásicos de sepsis, sepsis grave y shock séptico), ya que la posibilidad de bacteriemia aumenta según lo hace la gravedad clínica ${ }^{4}$. De forma que, inicialmente para las neumonías y las infecciones del tracto urinario (también en nuestro entorno las dos causas más frecuentes de bacteriemia y sepsis grave $)^{8,9}$, y posteriormente para todos los pacientes con infección, hemos adaptado a nuestro SU las recomendaciones publicadas en la revista de la Sociedad Española de Enfermedades Infecciosas y Microbiología Clínica (SEIMC) ${ }^{6}$ (Tabla 1).

Por otro lado, en numerosos SU ya se ha implantado el "código sepsis (CS)" (iniciativa española a la que se han sumado múltiples Sociedades Científicas Internacionales, entre ellas la Sociedades Chilenas de Medicina Intensiva y la de Medicina de Urgencias y, esperamos que también pronto, la Sociedad Chilena de Infectología). Desde que funciona el CS en nuestro SU hace más de dos años, que incluye el conocido como "triaje dirigido o avanzado" donde en la primera valoración ya se extrae la analítica, lactato y procalcitonina y, si existen datos de sospecha, los hemocultivos (Tabla 1), la mejora en todos los resultados de los distintos indicadores ha sido significativa. A modo de ejemplo, y prueba de la ayuda individual que una sola variable objetiva puede proporcionar (en este caso la procalcitonina), con un punto de corte de $1,16 \mathrm{ng} / \mathrm{ml}$ para las infecciones urinarias ${ }^{8}$ se obtiene un valor predictivo negativo (VPN) ("o lo que sería lo mismo que descartar la sospecha de bacteriemia") de casi $100 \%$ (de $94 \%$ si el punto de corte es $0,5 \mathrm{ng} / \mathrm{ml}$ ) y para las neumonías ${ }^{9}$ con punto de corte de $0,95 \mathrm{ng} / \mathrm{ml}$ se obtiene un VPN $>98 \%$ y de $92 \%$ si el corte elegido es $0,5 \mathrm{ng} / \mathrm{ml}$. Es decir, en ambos procesos muy relacionado a las concentraciones de $0,5-1 \mathrm{ng} / \mathrm{ml}$, como se recomienda en general para los distintos procesos infecciosos ${ }^{6}$. De esta forma a través del CS y del triaje avanzado se han conseguido distintos campos de mejora: se ha adecuado la indicación de la toma de hemocultivos, la administración precoz del antimicrobiano, el cumplimiento de todas las medidas diagnóstico-terapéuticas del CS y con ello han mejorado los resultados de morbi-mortalidad. En relación con la predicción de bacteriemia, cuando comparamos los dos años anteriores y los dos posteriores a la recomendación de toma de hemocultivos y sospecha de bacteriemia con procalcitonina $>1 \mathrm{ng} / \mathrm{ml}$, los pacientes con confirmación posterior de bacteriemia disminuyeron de 6 a $0,5 \%$, $(\mathrm{p}<0,01)$. Ello refuerza la idea de la utilidad y la ayuda que podría aportar este biomarcador a los modelos de 
predicción de bacteriemia, tal y como han sugerido otros autores $^{3}$.

En un futuro próximo seguramente otras variables, biomarcadores, nuevas técnicas moleculares, etc., se incorporarán a los modelos predictivos dirigidos y orientados desde el triaje avanzado del CS en los SU. Hasta entonces, tenemos la obligación de seguir investigando y colaborando juntos para mejorar la atención de los pacientes con infección que atendemos en los SU.

\section{Referencias bibliográficas}

1.- Cuervo A, Correa J, Garcés D, Ascuntar J, León A, Jaimes F A. Desarrollo y validación de un modelo predictor para bacteriemia en pacientes hospitalizados por el servicio de urgencias con sospecha de infección. Rev Chilena Infectol 2016; 33: 150-8

2.- Shapiro N I, Wolfe R E, Wright S B, Moore R, Bates D W. Who needs a blood culture? A prospectively derived and validated prediction rule. J Emerg Med 2008; 35: 255-64.

3.- Tudela P, Lacoma A, Pract C, Mòdol J M, Giménez M, Barallat J, et al. Predicción de bacteriemia en los pacientes con sospecha de infección en urgencias. Med Clin (Barc) 2010; 135: 685-90.

4.- Julián-Jiménez A, Laserna-Mendieta E J, Timón-Zapata J, Cabezas-Martínez A. Importancia de la sospecha clínica y confirmación de bacteriemia en los servicios de urgencias. Med Clin (Barc). 2011; 137: 426-7.

5.- Almela A, Millán J, Sorando R, Cano M J, Llorens P, Beltrán A. Proyecto PIPA: consenso de recomendaciones y propuestas de mejora para el manejo del paciente anciano con sospecha de infección en los servicios de urgencias de la Comunidad Valenciana. Emergencias 2015; 27: 87-94.

6.- Julián-Jiménez A, Candel-González F J, González del Castillo J. Utilidad de los biomarcadores de inflamación e infección en los servicios de urgencias. Enferm Infecc Microbiol Clin 2014; 32: 177-90.

7.- Monclús E, Nicolás D, Sánchez M, Ortega M. Detección mediante encuesta de las dificultades con las que se encuentra el personal sanitario en la prescripción y administración de antibióticos en la práctica clínica diaria de un servicio de urgencias hospitalario. Emergencias. 2015; 27: $50-4$.

8.- Julián-Jiménez A, Gutiérrez P, Lizcano A, López M A, Barroso A, Heredero E. Utilidad de la procalcitonina y proteína $\mathrm{C}$ reactiva para predecir bacteriemia en las infecciones del tracto urinario en el servicio de urgencias. Actas Urol Esp 2015; 39: 502-10.

9.- Julián-Jiménez A, Timón-Zapata J, Laserna-Mendieta E J, Parejo R, Flores-Chacartegui M, Gallardo P. Capacidad de la procalcitonina para predecir bacteriemia en pacientes con neumonía adquirida en la comunidad. Med Clin (Barc) 2014; 142: 285-92

10.- Carballo Cardona C. Triaje avanzado: es la hora de dar un paso adelante. Emergencias 2015; 2 7: 332-5.

Agustín Julián-Jiménez Servicio de Urgencias, Complejo Hospitalario de Toledo, Toledo, España.

Correspondencia a: agustinj@sescam.jccm.es

Corrección al abstract del artículo: Parechovirus como agente etiológico de meningitis y/o sepsis viral en lactantes, de Valentina Gutiérrez y cols., Rev Chilena Infectol 2016; 4: 380-8

\section{Debe decir:}

Introduction: Human parechovirus $(\mathrm{HPeV})$ belongs to the Picornaviridae family and has been described in viral meningoencephalitis ans sepsis like illness in infants. Until now, 16 genotypes have been recognized, the most common are $\mathrm{HPeV} \mathrm{1,} 2$ and 3; type 3 is most severe. Aims: To estimate the frequency of $\mathrm{HPeV}$ etiology in viral meningoencephalitis and sepsis in infants and characterize clinical and molecular aspects of infection. Methods: Between October 2013 and March 2015 we collected CSF samples, plasma, nasopharyngeal swabs and/or stools of patients younger than two years with suspected sepsis and/or viral meningitis. Samples were obtained from laboratory storage sites and from hospitalized patients. $\mathrm{HPeV}$ was diagnosed by real-time polymerase chain reaction (PCR) assay against the 5 'UTR region. Positive samples were genotyped by sequencing a $304 \mathrm{pb}$ segment in VP3/VP1 overlapping region obtained with a nested PCR. Results: Overall $\mathrm{HPeV}$ detection rate was 18,6\% (11/59 patients), distributed in $8.7 \%(4 / 46)$ laboratory's samples and 53.8\% (7/13) of samples from hospitalized patients; mean age was 49 days (18 days-6 months). Most common clinical signs (11/11 patients) were irritability, inappetance, and fever (magnitude $38-38.8^{\circ} \mathrm{C}$ ). All six samples genotyped were $\mathrm{HPeV}$ 3. Conclusions: $\mathrm{HPeV}$ should be considered as a relatively significant etiologic agent of viral meningoencephalitis and sepsis in infants. 